Vol. 1 No. 1, Hal 31 - 44

\title{
Analisis Pengendalian Mutu pada Proses Produksi Pembuatan Kecap Menggunakan Metode Fault Tree Analysis (FTA) dan Metode Failure Mode Efect Analysis (FMEA)
}

\author{
Akbar Supriadi ${ }^{1}$, Daonil ${ }^{* 2}$, Iskandar Zulkarnaen ${ }^{3}$ \\ Program Studi Teknik Industri, Fakultas Teknik, Universitas Bhayangkara Jakarta Raya \\ e-mail: ${ }^{1}$ akbar.supriadi1230@gmil.com, ${ }^{* 2}$ daonil@dsn.ubharajaya.ac.id, \\ 3iskandar.zulkarnaen@dsn.ubharajaya.ac.id
}

\begin{abstract}
Analysis of Quality Control in the Production Process of Making Soy Sauce Using the Fault Tree Analysis (FTA) Method and the Failure Mode Effect Analysis (FMEA) Method. PT XYZ is an industrial company that produces soy sauce and soy sauce for instant noodle seasoning. In an effort to maintain product quality, the writer tries to analyze every problem of reject burn, reject divert, organoleptic reject, and contaminated reject that exceeds the company standard of $0.50 \%$ based on histogram data for May 2018 - April 2019, it is found that organoleptic reject is the highest failure and the main problem is discussed using the fault tree analysis (FTA) method to analyze the root cause of failure, and the failure mode effect analysis (FMEA) method for weighting the severity, occurance and detection values in each of these three issues each problem is calculated to obtain a risk priority number (RPN) value ). From this data, it will be known that the root of the problem is the steam engine temperature value of 144 is the highest value of rpn, and the writer tries to give a proposal to improve the previous total reject $244,425 \mathrm{~kg}$ percentage $0.65 \%$ and after $69,284 \mathrm{~kg}$ percentage $0.36 \%$ with the cost before the total repair is Rp. 881,840,120 and after Rp.255,474,078 succeeded in reducing rejects below the standard while reducing costs for Rp.626,366,042.
\end{abstract}

Keyword : Reject, Soy Sauce, FTA, FMEA

\begin{abstract}
ABSTRAK
Analisis Pengendalian Mutu Pada Proses Produksi Pembuatan Kecap Menggunakan Metode Fault Tree Analysis (FTA) dan Metode Failure Mode Effect Analysis (FMEA). PT XYZ merupakan perusahaan industri yang menghasilkan produk kecap manis dan kecap asin untuk bumbu mie instant. Dalam upaya mempertahankan kualitas produk penulis berusaha untuk menganalisa setiap permasalahan reject gosong, reject divert, reject organoleptik, dan reject terkontaminasi yang melebihi standar perusahan $0,50 \%$ berdasarkan data histogram periode mei 2018 - april 2019 didapatkan reject organoleptik menjadi kegagalan tertinggi dan masalah utama yang dibahas dengan menggunakan metode fault tree analysis (FTA) untuk menganalisa akar penyebab kegagalan, dan metode failure mode effect analysis (FMEA) untuk pembobotan nilai severity, occurance dan detection di dalam ketiga hal tersebut setiap permasalah tersebut dihitung hingga mendapatkan nilai risk priority number (RPN). Dari data tersebut selanjutnya akan diketahui akar permasalahan tersebut adalah mesin steam suhu nilai 144 merupakan nilai rpn tertinggi, selanjutnta penulis mencoba memberikan usulan perbaikan sebelumnya total reject $244.425 \mathrm{~kg}$ persentase $0.65 \%$ dan sesudah $69.284 \mathrm{~kg}$ persentase $0.36 \%$ denga biaya sebelum perbaikan total Rp. 881.840.120 dan sesudah Rp.255.474.078 berhasil menurunkan reject dibawah standar sekaligus menurunkan biaya pengeluran sebesar Rp.626.366.042.
\end{abstract}

Kata Kunci : Reject, Kecap, FTA, FMEA

\section{PENDAHULUAN}

Perusahaan PT. XYZ ini masih mempunyai permasalahan pada banyaknya jenis reject yang disebabkan oleh berbagai macam faktor yang menyebabkan penurunan kualitas dan menurunya keuntungan yang didaptkan perusahaan Untuk mengetahui 
permasalahan, dibutuhkan suatu metode yang tepat untuk mencari akar masalah dari penyebeb kecacatan produk pada perusahaan ini. Bahan baku yang digunakan adalah Sari Kecap Manis (SKM), Gula Kelapa, Gula Tebu, Msg, Premiks, Garam, Gula Pasir, dan Air. Pada proses produksi pembuatan kecap ada beberapa tahapan dalam pembuatan kecap :

1. Proses Masak Olah Sari yaitu proses dimana pembuatan sari kecap jadi (SKJ), dan pembuatan larutan garam. Proses ini adalah tahapan awal dalam membuat kecap yang akan dilanjutkan ke tahap proses masak disolver dan eksentrik.

2. Proses Masak Disolver dan Eksentrik yaitu proses masak disoler dimana proses pelarutan bahan pembuatan kecap akan langsung melalui proses eksentrik untuk dilakukan penyaringan pada proses pelarutan yang dilakukan. Proses ini adalah tahapan ke dua yang akan dilanjutkan ke tahap proses masak blending.

3. Proses Masak Blending yaitu proses dimana pembuatan kecap mentah dan penambahan bahan baku yang juga akan dilakukan penyaringan agar tidak ada bahan sisa dalam pembuatan kecap pada tahapan proses masak blending. Proses ini adalah tahapan ke tiga yang akan dilanjutkan ke tahap proses masak pasteurisasi.

4. Proses Masak Pasteurisasi yaitu proses dimana pembuatan kecap mentah menjadi kecap mateng yang akan melalui beberapa proses. Proses ini adalah tahap ke akhir yang akan dilanjutkan ke penyimpanan tangki kecap.

Namun pada pelaksanaan produksinya masih terdapat hasil kegagalan produk kecap yang dihasilkan seperti reject gosong, divert, organoleptik, dan terkontaminasi. Data produksi kecap 12 bulan seperti pada tabel berikut ini :

Produksi kecap selama 12 bulan dengan total produksi $37.497 .000 \mathrm{~kg}$ dan total reject sebesar $244.425 \mathrm{~kg}$ dengan persentase $0,65 \%$. Permasalahan yang timbul akibat reject tersebut, sebab yang diberlakukan oleh kebijakan perusahaan hanya $0,50 \%$ dalam satu bulan. Pada bulan maret mengalami jumlah reject tertinggi sebesar $49.060 \mathrm{~kg}$ dengan persentase $1.64 \%$. Dari hasil tersebut dapat disimpulkan bahwa pengendalian mutu pada kualitas produk kecap mengalami penurunan kualitas pada produk yang dihasilkan.

\section{METODE PENELITIAN}

\subsection{Pengertian Kualitas}

Menurut Hendy Tannady (2015) Kualitas adalah suatu istilah yang sangat bergantungan pada situasi. Ditinjau dari arah pandang konsumen, secara subjektif orang mengatakan kualitas adalah sesuatu yang sesuai dengan serta (fitness for use). Suatu produk dikatakan berkualitas apabila produk tersebut mempunyai kesesuain penggunaaan bagi dirinya. Arah pandang yang berbeda mengatakan kualitas adalah produk atau jasa yang dapat meningkatkan status pemakaian.

\subsection{Fault Tree Analysis (FTA)}

Dikutip dari (Bayu, 2018) Fault

Tree Analysis (FTA) adalah suau analisa pohon kesalahan secara sederhana dapat diuraikan suatu teknik analitis. Pohon kesalahan suatu model grafis yang menyangkut berbagai parallel dan kombinasi percontohan kesalahan kesalahan yang akan mengakibatkan kejadian dari peristiwa tidak diinginkan yang sudsh didefinisi sebelumnya, atau juga dapat diartikan merupakan gambaran hubungan timbal balik yang logis dari peristiwa - peristiwa dasar yang mendorong.

Menurut (Gasperz, 2012) Failure Mode Effect Analysis (FMEA) adalah pendekatan sistematik yang menerapkan suatu metode pentabelan untuk membantu proses pemikiran yang digunakan oleh engineers untuk 
mengidentifikasi mode kegagalan potensial dan efeknya.

3 Langkah-langkah Dasar Failure Mode Effect Analysis (FMEA)

Terhadap langkah-langkah dasar dalam proses Failure Mode Effect Analysis (FMEA) yaitu sebagai berikut (Gasperz, 2012):

1. Mengidentifikasi fungsi pada proses produksi.

2. Mengidentifikasi potensi failure mode proses produksi.

3. Mengidentifikasi potensi efek kegagalan produksi.

4. Mengidentifikasi penyebabpenyebab kegagalan proses produksi.

5. Mengidentifikasi mode-mode deteksi proses produksi.

6. Menentukan rating terhadap severity, occurance, detection dan RPN proses.

7. Usulan perbaikan.

Tingkat Keparahan (Severity)

(Gasperz, 2012) Severity adalah

penilaian terhadap keseriusan dari efek yang ditimbulkan. Dampak tersebut diranking mulai skala 1 sampai 10 merupakan dampak terburuk.

Tingkat Kejadian (Occurrance)

Occurrence kemungkinan penyebab tersebut akan terjadi dan menghasilkan bentuk kegagalan selama masa penggunaan produk (Gasperz, 2012). Apabila sudah ditentukan rating pada proses severity, maka tahap selanjutnya adalah menentukan rating terhadap nilai occurrence sebagai berikut tabel 1 .

Mode Deteksi (Detection)

Nilai detection diasiosikan dengan pengendalian saat ini, identic dengan pemahaman sumber resiko. Deteksi adalah pengukuran terhadap kemampuan/mengontrol kegagalan yang dapat terjadi (Gasperz, 2012).

Bagaimana suatu kegagalan atau penyebab dapat terdeteksi sebelum masuk proses selanjutnya, penentuan nilai detection bisa dilihat pada tabel 2

Tabel 1 Kriteria Nilai Occurrence

\begin{tabular}{|c|c|c|c|}
\hline Ranking & Kejadian & Kriteria & Tingkat \\
\hline 1 & $\begin{array}{l}\text { Hampir tidak } \\
\text { pernah }\end{array}$ & $\begin{array}{c}\text { Kerusakan hampir tidak } \\
\text { pernah terjadi }\end{array}$ & $\begin{array}{c}\text { Lebih besar dari } 10.000 \\
\text { jam operasi mesin }\end{array}$ \\
\hline 2 & Remote & Kerusakan jarang terjadi & $\begin{array}{c}\text { 6.001-10.000 jam operasi } \\
\text { mesin }\end{array}$ \\
\hline 3 & Sangat sedikit & $\begin{array}{c}\text { Kerusakan terjadi sangat } \\
\text { sedikit }\end{array}$ & $\begin{array}{c}\text { 3.001-6.000 jam operasi } \\
\text { mesin }\end{array}$ \\
\hline 4 & Sedikit & Kerusakan terjadi sedikit & $\begin{array}{l}\text { 2.001-3.000 jam operasi } \\
\text { mesin }\end{array}$ \\
\hline 5 & Rendah & $\begin{array}{l}\text { Kerusakan terjadi pada } \\
\text { tingkat rendah }\end{array}$ & $\begin{array}{c}\text { 1.001-2.000 jam operasi } \\
\text { mesin }\end{array}$ \\
\hline 6 & Medium & $\begin{array}{l}\text { Kerusakan terjadi pada } \\
\text { tingkat medium }\end{array}$ & $\begin{array}{c}401-1.000 \text { jam operasi } \\
\text { mesin }\end{array}$ \\
\hline 7 & Agak tinggi & $\begin{array}{c}\text { Kerusakan terjadi agak } \\
\text { tinggi }\end{array}$ & 101-400 jam operasi mesin \\
\hline 8 & Tinggi & Kerusakan terjadi tinggi & 11-100 jam operasi mesin \\
\hline 9 & Sangat tinggi & $\begin{array}{c}\text { Kerusakan terjadi sangat } \\
\text { tinggi }\end{array}$ & 2-10 jam operasi mesin \\
\hline 10 & Hampir selalu & Kerusakan selalu terjadi & $\begin{array}{c}\text { Kurang dari } 2 \text { jam operasi } \\
\text { mesin }\end{array}$ \\
\hline
\end{tabular}

Sumber: Gasperz (2012) 
Tabel 2 Mode Detection

\begin{tabular}{|c|l|}
\hline $\begin{array}{c}\text { SKOR } \\
\text { DETECTION }\end{array}$ & \multicolumn{1}{|c|}{ Kemampuan metode deteksi terhadap resiko } \\
\hline 1 atau 2 & $\begin{array}{l}\text { Metode deteksi sangat efektif dan hampir pasti resiko akan } \\
\text { terdeteksi dengan waktu yang cukup melaksanakan rencana } \\
\text { komtigensi }\end{array}$ \\
\hline 3 atau 4 & Metode deteksi memiliki tingkat efektifitas yang tinggi \\
\hline 5 atau 6 & $\begin{array}{l}\text { Metode deteksi memiliki tingkat efektifitas yang rata-rata } \\
\text { medium }\end{array}$ \\
\hline 7 atau 8 & $\begin{array}{l}\text { Metode deteksi tidak terbukti atau relatif, metode deteksi } \\
\text { tidak diketahui untuk mendeteksi tepat waktu }\end{array}$ \\
\hline 9 atau 10 & $\begin{array}{l}\text { Tidak ada metode deteksi, mode deteksi yang tidak mampu } \\
\text { memberikan cukup waktu melaksanakan rencana } \\
\text { kontinguensi }\end{array}$ \\
\hline
\end{tabular}

Sumber: Gasperz (2012)

\subsection{Risk Priority Number (RPN)}

Menurut Gasperz (2012) nilai ini merupakan produk dari hasil perkalian tingkat keparahan, tingkat kejadian dan tingkat deteksi. RPN menentukan prioritas dari kegagalan. Setelah mendapatkan nilai severity, occurrance dan detection akan diperoleh nilai RPN dengan cara mengalikan nilai severity, occurrence dan detection (RPN = SxOxD). Kemudian dilakukan pengurutan berdasarkan nilai RPN tertinggi sampai terendah.

\subsection{Cost of Poor Quality (COPQ)}

Cost of poor quality atau biaya akibat kualitas yang rendah merupakan pemborosan dalam organisasi, sehingga banyak perusahaan kelas dunia yang menerapkan program menggunakan indikator pengukuran biaya kualitas sebagai pengukuran kinerja efektifitas keberhasilan dari program yang ditetapkan (Gasperz, 2012). Gambar kerangka penelitian dapat dilihat pada Gambar 1

\section{HASIL DAN PEMBAHASAN}

Berdasarkan tabel produksi kecap selama 12 bulan dengan total produksi $37.497 .000 \mathrm{~kg}$ dan total reject sebesar $244.425 \mathrm{~kg}$ dengan persentase $0,65 \%$. Permasalahan yang timbul akibat reject tersebut, sebab yang diberlakukan oleh kebijakan perusahaan hanya $0,50 \%$ dalam satu bulan. Dari hasil tersebut dapat disimpulkan bahwa pengendalian mutu pada kualitas mengalami penurunan.

\subsection{Fault Tree Analysis (FTA)}

Dari hasil pembuatan diagram Fault Tree Analysis (FTA), maka didapatkan basic event untuk jenis reject organoleptik adalah sebagai berikut : Reject organoleptik didapat 7 basic event yang terjadi dari penyebab kegagalan, basic event kegagalan akibat formulasi pada garam identitas tidak jelas, dan penyimpanan pada gula belum tepat dan tidak dibuatkan jadwal pengecekan berkala. Basic event pada kegagalan mixing agitator terjadi mati /trip di sebabkan tidak ada intruksi kerja pergantian komponen dan tidak dibuatkan jadwal perawatan secara teratur. Basic event pada human eror disebabkan operator baru dan operator tergesa gesa mengejar target produksi.

Gambar 2
Gambar FTA dapat dilihat pada 


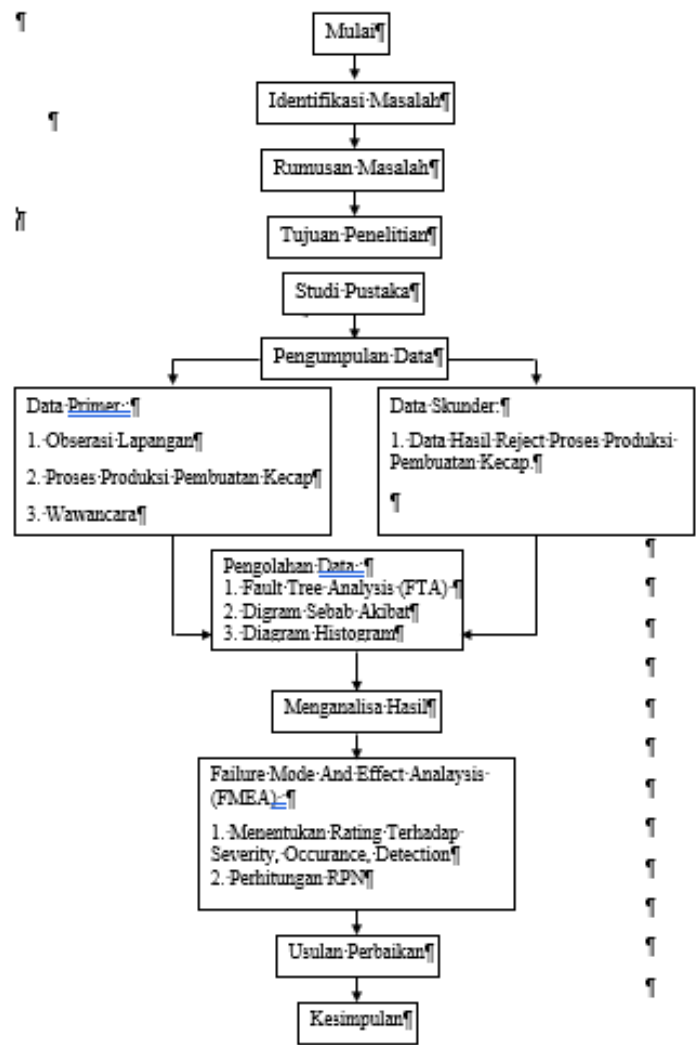

Sumber: Pengolahan Data (2019)

Gambar 1 Kerangka Penelitian

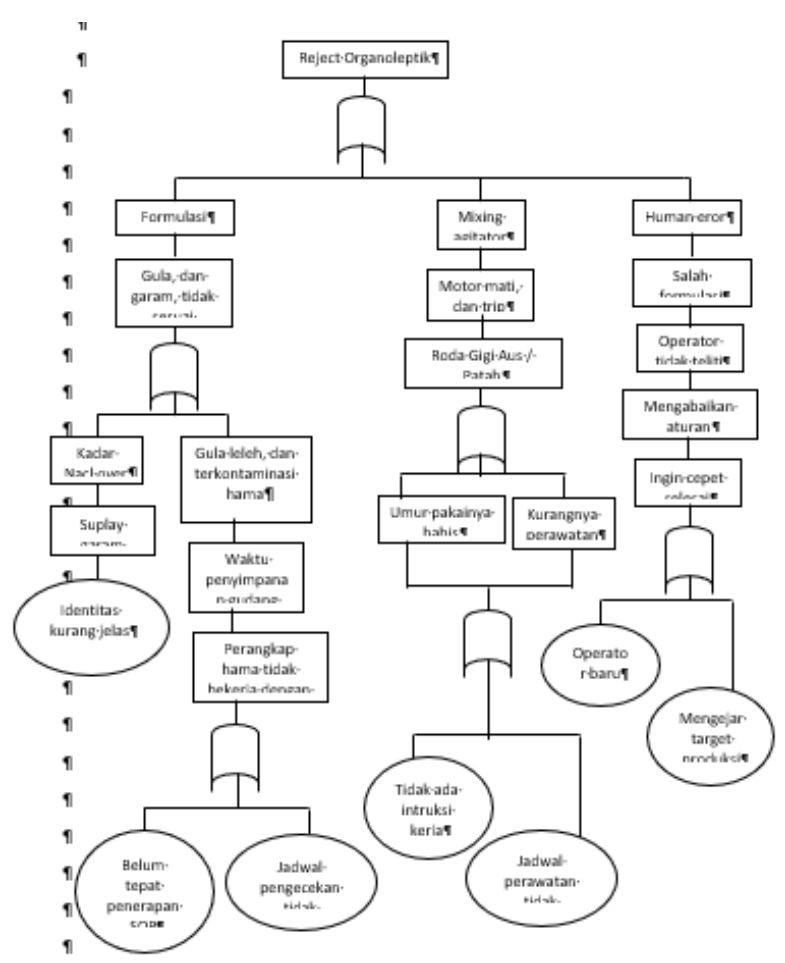

Sumber: Pengolahan Data (2019)

Gambar 2. Fault Tree Analysis 


\subsection{Risk Priority Number (RPN)}

Berikut adalah tabel Risk

Priority Number dari hasil identifikasi pada nilai Severity, Occurance, Detection, selanjutnya adalah menghitung nilai keseluruhan dari RPN dengan rumus $\mathrm{RPN}=\mathrm{S} \times \mathrm{O} \times \mathrm{D}$, kemudian dibuatkan tabel perhitungan niali RPN pada kasus produk pembuatan kecap dengan pengukuran berdasarkan nilai RPN tertinggi dan terendah. Perhitungan RPN dapat dilihat pada Tabel 3

\subsection{Perhitungan Biaya Perbaikan}

Pada penelitian ini dapat dihitung dari hasil reject organoleptik yang dihasilkan oleh proses masak disolver yang mengakibatkan perlu adanya proses repair pada produk kecap. Dari berbagai macam jenis reject yang dihasilkan berbeda beda pula lama waktu pengerjaan yang dibutuhkan untuk proses repair atau perbaikannya. Untuk jenis Reject Gosong memerlukan waktu 60 menit $/ \mathrm{kg}$, Reject Divert 45 menit $/ \mathrm{kg}$, Reject Organoleptik 90 menit $/ \mathrm{kg}$, dan Reject Terkontaminasi yaitu 30 menit $/ \mathrm{kg}$. Karena padatnya tingkat produksi yang ada di PT.XYZ maka pengerjaan repair dilakukan pada saat jam lembur ( Overtime ). Berikut perhitungan perbaikan rework produk kecap di PT.XYZ sebagai berikut adalah rumus perhitungan biaya, yaitu :

Cost repair per jam : =

$\frac{\text { Gaji Karyawan }}{\text { Jumlah Kerja dalam } 1 \text { Bulan }} 7$ jam

Biaya Repair : =

Total Reject x Waktu Perbaikan 900 Detik

Biaya Dalam 1 Bulan = ( Biaya Perbaikan ) x ( Overtime dikali 2 )

Diketahui :
1. Gaji karyawan di PT. XYZ adalah Rp. 4.200.000,-

2. Jumlah hari kerja dalam 1 bulan adalah 22 Hari

3. Jumlah jam kerja dalam 1 hari adalah 7 jam

\section{Estimasi Biaya Perbaikan Bulan Mei} 2018 - April 2019

1. Diketahui :

Waktu Repair Reject Organoleptik /

$\mathrm{Kg}=90$ Menit

Waktu Repair dilakukan pada jam lembur ( Overtime )

dikali 2 Jumlah Defect Reject

Organoleptik bulan mei

adalah $=5250 \mathrm{Kg}$

2. Perhitungan Biaya Repair dalam sehari :

Biaya perjam $=\frac{4.200 .000}{22 \mathrm{Hari}} / 7 \mathrm{jam}=$ Rp. 27.272

3. Perhitungan Biaya Repair dalam 1 $\mathrm{Kg}$ :

Biaya Repair $=\frac{5.250 \times 90}{900 \text { Detik }} \times \mathrm{Rp}$.

27.272 = Rp. 14.317.000

4. Perhitungan Biaya dalam 1 Bulan :

Biaya 1 bulan $=$ Rp. $14.317 .000 \times 2$ $=$ Rp. 28.635 .600

Berdasarkan hasil perhitungan diatas maka didapat biaya perbaikan reject organoleptik hasil proses masak dissolver pada produk kecap pada bulan Mei 2018 sebesar Rp. 28.635.600. Cost Perbaikan Gosong Rp. 14.363.253 + Cost Perbaikan Divert Rp. 10.227.000 + Cost Perbaikan 28.635.600 + Cost Perbaikan Organoleptik Rp. 28.635.600 + Cost Perbaikan Terkontaminasi Rp. 4.008.984 $=$ Total Cost Perbaikan Bulan Mei 2018 adalah Rp 57.234.837. Tabel 4 merupaka tabel Total Perkiraan Cost Perbaikan Bulan Mei 2018 - April 2019 dan Gambar 3 Grafik Total Cost Perbaikan Mei 2018 - April 2019

Tabel 3 Perhitungan Risk Priority Number (RPN)

\begin{tabular}{|c|c|c|c|c|}
\hline No & Key Proses Input (Indikator) & Proses & S X O X D & RPN \\
\hline 1 & Operator (Man Power) & \multirow{3}{*}{ Disolver } & $6 \times 2 \times 2$ & 24 \\
\hline 2 & $\begin{array}{c}\text { Raw Material (Gula, Garam Air, } \\
\text { dan Sari) }\end{array}$ & & $5 \times 3 \times 3$ & 45 \\
\hline 3 & Mesin Mixing Agitator & & $7 \times 6 \times 3$ & 126 \\
\hline
\end{tabular}




\begin{tabular}{|c|c|c|c|c|}
\hline 4 & Mesin Steam Suhu & $8 \times 6 \times 3$ & 144 \\
\hline 5 & $\begin{array}{c}\text { Area Mesin Disolver Tidak } \\
\text { Safety/ Kotor }\end{array}$ & $6 \times 5 \times 2$ & 60 \\
\hline \multirow{nnnn}{nnn}{6} & $\begin{array}{l}\text { SOP (Standar Operational } \\
\text { Prosedur) }\end{array}$ & $5 \times 4 \times 2$ & 40 \\
\hline
\end{tabular}

Sumber: Pengolahan Data (2019)

Tabel 4 Total Perkiraan Cost Perbaikan Bulan Mei 2018 - April 2019

\begin{tabular}{|c|c|c|c|c|}
\hline NO & BULAN & $\begin{array}{l}\text { JUMLAH HASIL } \\
\text { PRODUKSI (kg) }\end{array}$ & $\begin{array}{c}\text { JUMLAH } \\
\text { REJECT }(\mathrm{kg})\end{array}$ & $\begin{array}{l}\text { COST PERBAIKAN } \\
(\mathrm{Rp})\end{array}$ \\
\hline 1 & Mei 2018 & 2.984 .500 & 15.155 & 57.234 .837 \\
\hline 2 & Juni 2018 & 3.481 .000 & 18.040 & 69.252 .699 \\
\hline 3 & Juli 2018 & 3.005 .500 & 16.125 & 60.589 .293 \\
\hline 4 & Agustus 2018 & 3.082 .500 & 15.720 & 58.852 .976 \\
\hline 5 & September 2018 & 2.986 .500 & 16.780 & 63.734 .664 \\
\hline 6 & Oktober 2018 & 3.028 .500 & 19.250 & 73.270 .773 \\
\hline 7 & November 2018 & 3.036 .000 & 18.100 & 67.089 .120 \\
\hline 8 & Desember 2018 & 3.013 .500 & 15.560 & 60.652 .928 \\
\hline 9 & Januari 2019 & 3.450 .500 & 18.550 & 70.634 .480 \\
\hline 10 & Februari 2019 & 3.063 .500 & 23.100 & 90.543 .040 \\
\hline 11 & Maret 2019 & 2.998 .500 & 49.060 & 135.560 .021 \\
\hline 12 & April 2019 & 3.366 .500 & 18.985 & 74.425 .288 \\
\hline \multicolumn{2}{|r|}{ TOTAL } & 37.497 .000 & 244.425 & 881.840 .120 \\
\hline
\end{tabular}

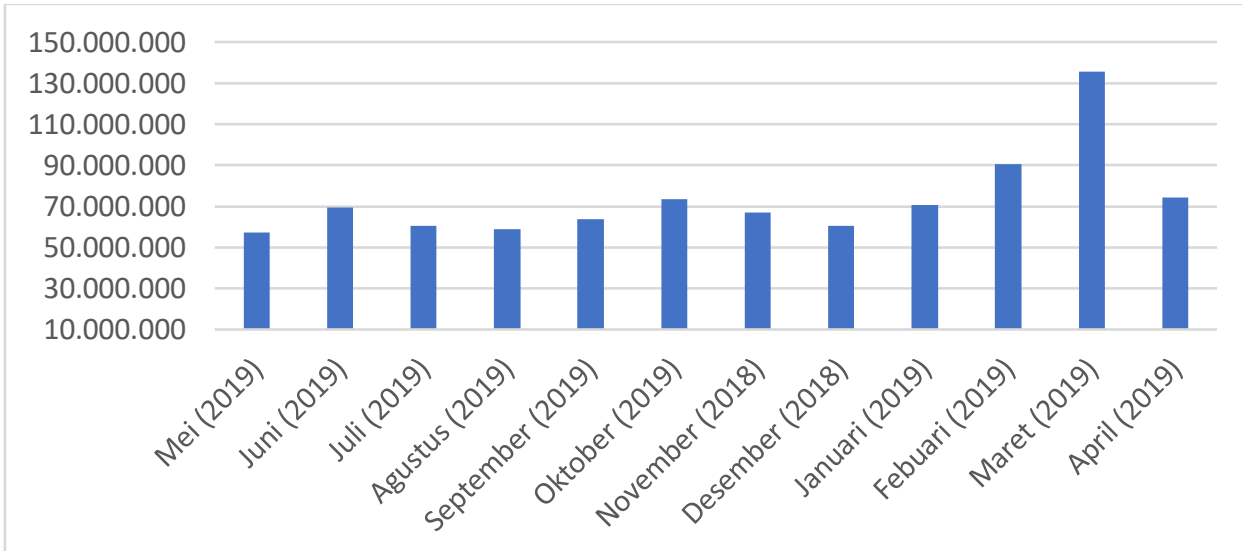

Sumber: Pengolahan Data (2019)

Gambar 3 Grafik Total Cost Perbaikan Mei 2018 - April 2019 Sumber : PT. XYZ

3.4 Usulan Perbaikan

Berdasarkan hasil analisa menggunakan metode fault tree analysis dan metode failure mode effect analysis serta diagram sebab akibat dan $5 \mathrm{~W}+2 \mathrm{H}$ yang penulis lakukan dengan mengikut sertakan perwakilan dari department terkait untuk mengatasi mode kegagalan yang ada pada produk kecap dengan jenis reject gosong, reject divert, reject organoleptik dan reject terkontaminasi didapatkan usulan perbaikan pada equipment mesin. Khususnya mesin dissolver pada proses masak produk kecap. Berikut adalah estimasi perkiraan biaya untuk perbaikan equipment tersebut. Tabel 5 adalah perkiraan biaya investasi Improvement. Berikut penjelasan kenapa harus dilakukan perbaikan pada equipment tersebut : 
1. Selang Ptfe Teflon Putih Ukuran 6 $\mathrm{mm}$

Dikarenakan proses penuangan GGAS menggunakan valve actuator pneumatic yang bekerja menggunakan tekanan angin untuk menurunkan GGAS pada daily tank sebelumnya menggunakan selang $\mathrm{Pu}$ (polyurethane) yang tidak tahan panas dan bahan sering berlubang, dan diperlukanya pengantian selang ptfe teflon putih yang berbahan tebel dan tahan terhadap panas.

2. Gasket Steam Teflon Ukuran 6 $\mathrm{mm}$

Pada saat proses pelarutan GGAS menggunakan pemanasan pada steam pada saat proses bekerja steam mengalami kebocoran yang disebabkan gasketnya terkikis terus menerus. Untuk itu dilakukan penggantian gasket steam it dengan gasket steam ptfe teflon yang berbahan tebel dan tidak mudah terkikis.

3. Globe steam valve Std 3 inch Pn 25 Pengantian type globe setam dan improve bertujuan untuk memastikan steam tertup rapat dengan otomatis pada suhu yang sudah ditentukan sebelumnya. Dan penggabungan antara globe steam valve dan valve controlli pada panel setelah dilakukan instal valve steam otomatis.

4. Valve controlli Improve, pemasangan bertujuan untuk mengendalikan suhu dan memastikan steam tertutup dengan otomatis melalui panel dissolver. Agar tidak terjadinya kelalaian operator pada saat penutup steam.

Tabel 5 Perkiraan Biaya Investasi Improvement

\begin{tabular}{|c|c|c|c|c|c|}
\hline No & Equipment & Gambar & $\begin{array}{l}\text { Jumlah } \\
\text { (Pcs) }\end{array}$ & $\begin{array}{c}\text { Harga satuan } \\
(\mathrm{Rp})\end{array}$ & Total (Rp) \\
\hline 1 & $\begin{array}{l}\text { Selang Ptfe } \\
\text { Teflon Putih } \\
\text { ukuran } 6 \mathrm{~mm} \\
\text { (100 meter) }\end{array}$ & & 2 & 5.548 .000 & 11.096 .000 \\
\hline 2 & $\begin{array}{l}\text { Gasket Steam } \\
\text { Teflon Ptfe } \\
\text { ukuran } 3 \mathrm{~mm} \text { (1 } \\
\text { x } 1 \text { meter) }\end{array}$ & & 2 & 689.000 & 1.378 .000 \\
\hline 3 & $\begin{array}{c}\text { Globe steam } \\
\text { valve Std } 3 \text { inch } \\
\text { Pn } 25\end{array}$ & & 2 & $7,500,000$ & 25.000 .000 \\
\hline 4 & Valve Controlli & & 1 & 15.000 .000 & 15.000 .000 \\
\hline
\end{tabular}




\begin{tabular}{|c|c|c|c|c|c|}
\hline 5 & $\begin{array}{c}\text { Instal panel } \\
\text { valve steam } \\
\text { otomatis (2Man } \\
\text { Power } \\
\text { Overtime) }\end{array}$ & 1 & 3.200 .000 \\
\hline 6 & Lain -lain & & & 20.000 \\
\hline \multicolumn{3}{|c|}{ TOTAL } & 55.694 .000 \\
\hline
\end{tabular}

3.5 Analisa Hasil Perbaikan

Setelah dilakukan analisa selama 6 bulan setelah proses perbaikan diambil data yang sama dan diolah dengan format yang sama, setelah dilakukan pengolahan data kemudian dilakukan analisis terhadap hasil yang telah didapatkan periode mei 2019 sampai dengan oktober 2019. Berikut adalah data hasil perbaikan yang diperoleh oleh department quality dapat dilihat pada tabel 6 , tabel 7 , dan tabel 8 .

Tabel 6 Data Reject Produk Kecap Mei 2019 - Oktober 2019

\begin{tabular}{|c|c|c|c|c|c|}
\hline NO & BULAN & $\begin{array}{l}\text { JUMLAH HASIL } \\
\text { PRODUKSI }(\mathrm{kg})\end{array}$ & $\begin{array}{c}\text { JUMLAH } \\
\text { REJECT }(\mathrm{kg})\end{array}$ & PERSENTASE & $\begin{array}{l}\text { STANDAR } \\
\text { PT }\end{array}$ \\
\hline 1 & Mei & 2.967 .000 & 12.905 & $0.43 \%$ & \multirow{7}{*}{$0.50 \%$} \\
\hline 2 & Juni & 3.115 .000 & 12.390 & $0.40 \%$ & \\
\hline 3 & Juli & 3.100 .500 & 11.565 & $0.37 \%$ & \\
\hline 4 & Agustus & 3.000 .500 & 10.190 & $0.34 \%$ & \\
\hline 5 & September & 2.988 .000 & 9205 & $0.31 \%$ & \\
\hline 6 & Oktober & 3.096 .500 & 8.615 & $0.28 \%$ & \\
\hline \multicolumn{2}{|r|}{ TOTAL } & 18.267 .000 & 69.284 & $0.36 \%$ & \\
\hline
\end{tabular}

Sumber : Pengolahan Data PT. XYZ (2019)

Tabel 7 Data Penyumbang Reject Produk Kecap Mei 2019 - Oktober 2019

\begin{tabular}{|c|c|c|c|c|c|c|c|c|c|c|}
\hline & \multirow{3}{*}{\multicolumn{2}{|c|}{ OSONG }} & \multirow{2}{*}{\multicolumn{6}{|c|}{ JENIS REJECT (KG) }} & \multirow{4}{*}{$\begin{array}{l}\text { TOTAL } \\
\text { REJECT }\end{array}$} & \\
\hline \multirow{3}{*}{ BULAN } & & & & & & & & & & \multirow{3}{*}{ RATIO } \\
\hline & & & \multicolumn{2}{|c|}{ DIVERT } & \multicolumn{2}{|c|}{ ORGANOLEPTIK } & \multicolumn{2}{|c|}{ TERKONTAMINASI } & & \\
\hline & Qty & $\%$ & Qty & $\%$ & Qty & $\%$ & Qty & $\%$ & & \\
\hline Mei & 3.390 & $0.11 \%$ & 3.280 & $0,11 \%$ & 4.980 & $0.17 \%$ & 1.255 & $0.04 \%$ & 12.905 & $0.43 \%$ \\
\hline Juni & 3.280 & $0.11 \%$ & 3.130 & $0.10 \%$ & 4.790 & $0.15 \%$ & 1.190 & $0.04 \%$ & 12.390 & $0.40 \%$ \\
\hline Juli & 3.070 & $0.10 \%$ & 2.940 & $0.09 \%$ & 4.410 & $0.14 \%$ & 1.145 & $0.04 \%$ & 11.565 & $0.37 \%$ \\
\hline Agustus & 2.600 & $0.09 \%$ & 2.560 & $0.09 \%$ & 4.070 & $0.14 \%$ & 960 & $0.03 \%$ & 10.190 & $0.34 \%$ \\
\hline September & 2.450 & $0.08 \%$ & 2.350 & $0.08 \%$ & 3.610 & $0.12 \%$ & 795 & $0.03 \%$ & 9.205 & $0.31 \%$ \\
\hline Oktober & 2.310 & $0.07 \%$ & 2.150 & $0.07 \%$ & 3.505 & $0.11 \%$ & 650 & $0.02 \%$ & 8.615 & $0.28 \%$ \\
\hline Total & 17.100 & $0.09 \%$ & 16.410 & $0.09 \%$ & 25.365 & $0.14 \%$ & 8.995 & $0.03 \%$ & 64.870 & $0.36 \%$ \\
\hline
\end{tabular}

Tabel 8 Data Total Produksi, Finish Good, dan Reject

\begin{tabular}{|c|c|c|c|c|}
\hline NO & BULAN & $\begin{array}{c}\text { TOTAL } \\
\text { PRODUKSI }\end{array}$ & $\begin{array}{r}\text { FINISH } \\
\text { GOOD }\end{array}$ & TOTAL REJECT \\
\hline 1 & MEI & 2.967 .000 & 2.954 .095 & 12.905 \\
\hline 2 & JUNI & 3.115 .000 & 3.102 .610 & 12.390 \\
\hline 3 & JULI & 3.100 .500 & 3.088 .935 & 11.565 \\
\hline 4 & AGUSTUS & 3.000 .500 & 2.990 .310 & 10.190 \\
\hline 5 & SEPTEMBER & 2.988 .00 & 2.978 .795 & 9.205 \\
\hline
\end{tabular}




\begin{tabular}{|c|c|c|c|c|}
\hline 6 & OKTOBER & 3.096 .500 & 3.087 .885 & 8.615 \\
\hline & TOTAL & 18.267 .500 & 18.202 .630 & 64.870 \\
\hline
\end{tabular}

Sumber : PT. Pengolahan Data XYZ (2019)

\section{Evaluasi Hasil Perbaikan}

Tabel 9 dan tabel 10 adalah tabel

Data Perbandingan Reject Sebelum Perbaikan dan Sesudah Perbaikan

Estimasi Biaya Perbaikan Bulan

Mei 2019 - Oktober 2019

1. Diketahui :

Waktu Repair Reject

Organoleptik / Kg = 90 Menit

Waktu Repair dilakukan

pada jam lembur ( Overtime

) dikali 2 Jumlah Defect

Reject Organoleptik bulan

Mei adalah $=4.980 \mathrm{Kg}$

2. Perhitungan Biaya Repair dalam sehari :

Biaya perjam $=\frac{4.200 .000}{22 \mathrm{Hari}} / 7 \mathrm{jam}$

= Rp. 27.272

3. Perhitungan Biaya Repair dalam 1 $\mathrm{Kg}$ :
Biaya Repair $=\frac{4.980 \times 90}{900 \text { Detik }} \times \mathrm{Rp}$.

$27.272=$ Rp. 13.581 .456

4. Perhitungan Biaya dalam 1 Bulan: Biaya 1 bulan $=$ Rp. $13.581 .456 \mathrm{x}$ $2=$ Rp. 27.162.912

Berdasarkan hasil perhitungan diatas maka didapat biaya perbaikan reject organoleptik hasil proses masak dissolver pada produk kecap pada bulan Mei 2019 sebesar Rp. Rp. 27.162.912 Cost Perbaikan Gosong Rp. 8.945.216 + Cost Perbaikan Divert Rp. 2.716.912+ Cost Perbaikan Organoleptik Rp. 28.635.600 + Cost Perbaikan Terkontaminasi Rp. 2.281.757 = Total Cost Perbaikan Bulan Mei 2019 adalah Rp 50.716.829. Tabel 11 Total Perkiraan Cost Perbaikan Bulan Mei 2019 Oktober 2019

Tabel 9 Data Perbandingan Reject Sebelum PerbaikanDan Sesudah Perbaikan

\begin{tabular}{|c|c|c|}
\hline \multicolumn{2}{|c|}{ Perbandingan Sebelum Perbaikan Dan Sesudah Perbaikan } \\
\hline & Jumlah Total Reject $(\mathrm{Kg})$ & Rata - Rata $(\mathrm{Kg})$ \\
\hline Sebelum Perbaikan & 244.425 & 20.369 \\
\hline Sesudah Perbaikan & 69.284 & 10.811 \\
\hline Total Nilai & 309.295 & 31.180 \\
\hline
\end{tabular}

Sumber : Pengolahan Data PT. XYZ (2019)

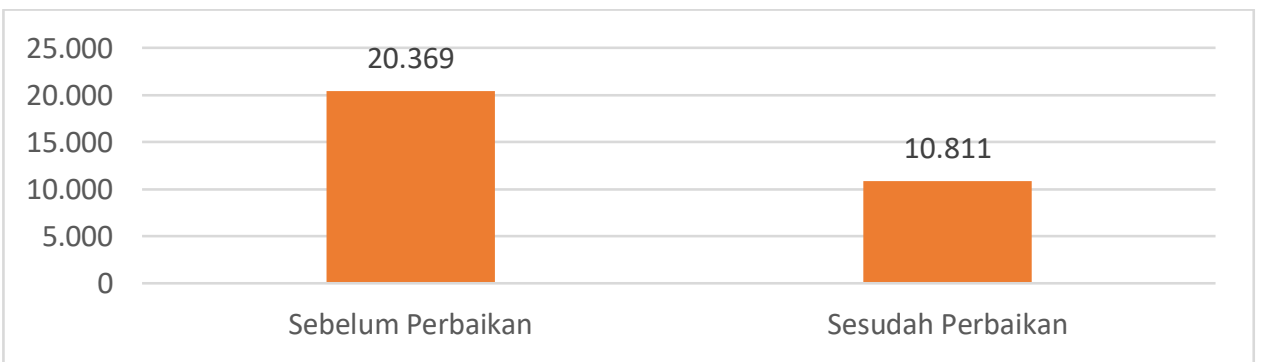

Sumber : PT. XYZ (2019)

Gambar 4 Persentase Perbandingan Rejecet Sebelum Dan Sesudah

Tabel 10 Data Perbandingan Cost Sebelum Dan Sesudah Perbaikan

\begin{tabular}{|c|c|c|}
\hline \multicolumn{3}{|c|}{ Perbandingan Sebelum Perbaikan Dan Sesudah Perbaikan } \\
\hline & Jumlah Total Cost $(\mathrm{Rp})$ & Rata - Rata $(\mathrm{Rp})$ \\
\hline Sebelum Perbaikan & 881.840 .120 & 73.486 .677 \\
\hline Sesudah Perbaikan & 255.374 .078 & 42.562 .346 \\
\hline Total Nilai & 1.137 .214 .198 & 116.049 .023 \\
\hline
\end{tabular}

Sumber : Pengolahan Data PT. XYZ (2019)

40 


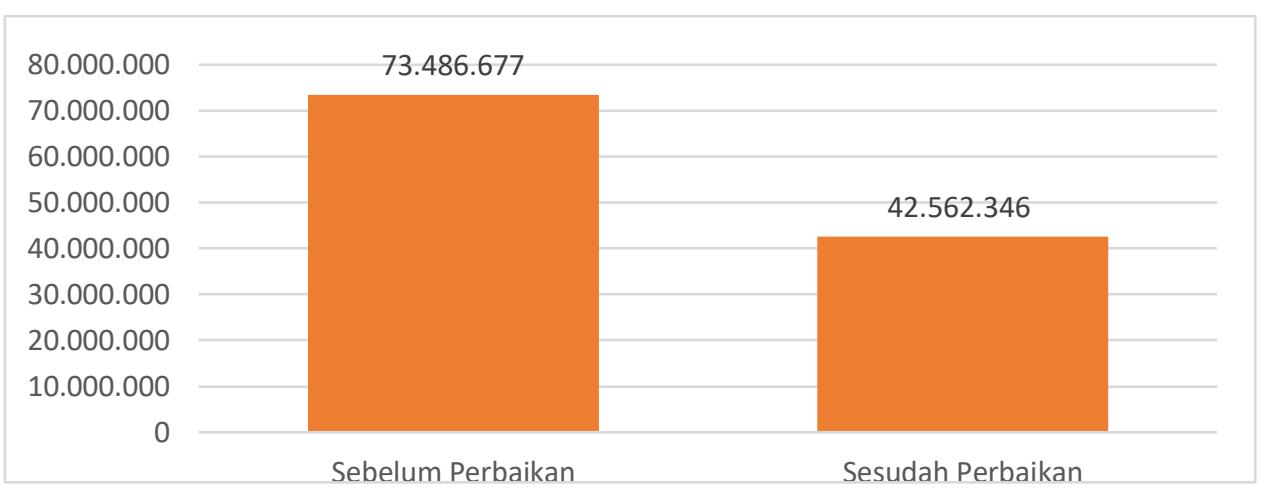

Sumber : Pengolahan Data PT. XYZ

Gambar 5 Persentase Perbandingan Cost Sebelum Dan Sesudah

Tabel 11 Total Perkiraan Cost Perbaikan Bulan Mei 2019 - Oktober 2019

\begin{tabular}{|c|c|c|c|c|}
\hline NO & Bulan & $\begin{array}{c}\text { Jumlah Hasil } \\
\text { Prodksi }(\mathrm{kg})\end{array}$ & $\begin{array}{c}\text { Jumlah Reject } \\
(\mathrm{kg})\end{array}$ & Cost Perbaikan (Rp) \\
\hline 1 & Mei 2019 & 2.967 .000 & 12.905 & 50.716 .829 \\
\hline 2 & Juni 2019 & 3.115 .000 & 12.390 & 48.753 .245 \\
\hline 3 & Juli 2019 & 3.100 .500 & 11.565 & 45.316 .973 \\
\hline 4 & Agustus 2019 & 3.000 .500 & 10.190 & 40.380 .741 \\
\hline 5 & September 2019 & 2.988 .500 & 9.205 & 36.453 .573 \\
\hline 6 & Oktober 2019 & 3.096 .500 & 8.615 & 34.562 .715 \\
\hline \multicolumn{2}{|c|}{ TOTAL } & 18.267 .000 & 69.284 & 255.374 .078 \\
\hline
\end{tabular}

Sumber : Pengolahan Data PT. XYZ (2019)

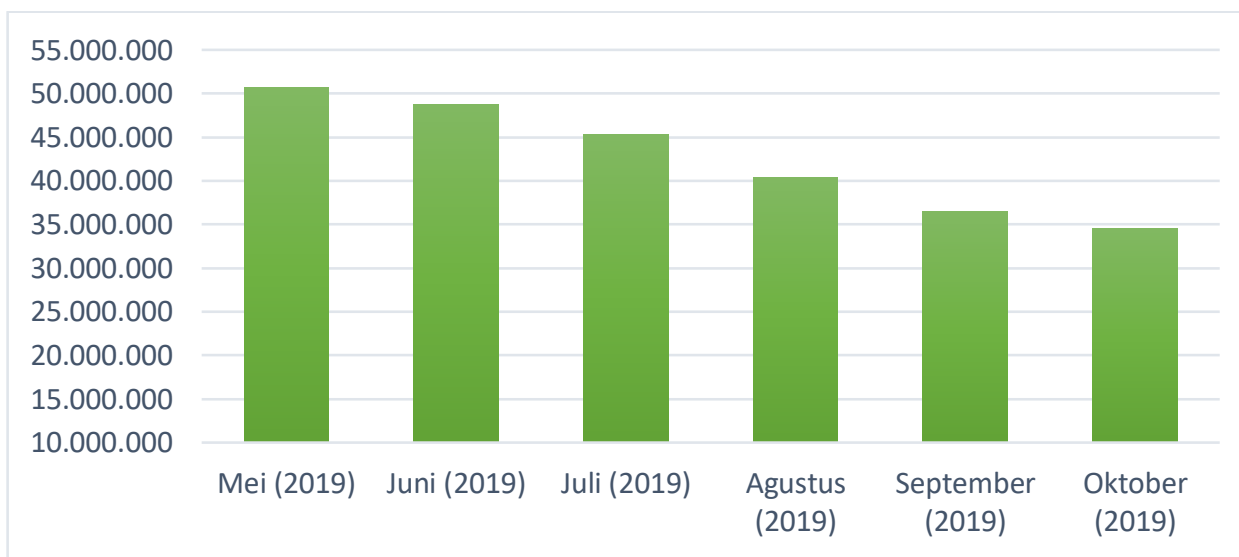

Sumber : Pengolahan Data PT. XYZ (2019)

Gambar 6 Graffik Total Cost Repair Selama 6 Bulan

Berdasarkan improvement yang dijalankan penulis memberikan data cost perbandingan antara sebelum dan sesudah improvement agar dapat memudahkan pembaca dalam memahami isi dari karya tulis ini. Hasil dari grafik usulan perbaikan diatas disimpulkan penuruan perbaikan yang sangat signifikan dari bulan mei 2019 sampai oktober 2019. Pada data sebelum perbaikan total reject selama 12 bulan $244.425 \mathrm{~kg}$ setelah perbaikan selama 6 bulan menjadi $69.284 \mathrm{~kg}$ hasil perbaikan yang dilakukan berhasil menurunkan $175.141 \mathrm{~kg}$. pada data sebelum perbaikan total cost selama 12 bulan Rp. 881.840.120 setelah perbaikan selama 6 bulan total cost selama 6 bulan $\mathrm{Rp}$. 
255.374.078 hasil perbaikan yang dilakuka berhasil menurunkan $\mathrm{Rp}$. 626.466.042.

\section{KESIMPULAN DAN SARAN}

\section{Kesimpulan}

Berdasarkan pembahasan penulis mengenai permasalahan kegagalan kecap reject dengan menggunakan metode fault tree analysis (FTA) dan metode failure mode effect analysis (FMEA) dari penelitian yang telah dilakukan penulis dapat ditarik kesimpulan faktor faktor yang menyebabkan terjadinya reject organoleptic pada saat proses masak kecap, yaitu: Steam suhu eror mengakibatkan material tidak dapat terlarut dan material menjadi gosong mengakibatkan terjadinya reject organoleptic, Mixing agitator eror mengakibatkan material tidak tercampur rata mengakibatkan terjadinya reject organoleptic, tidak adanya point pemakain steam suhu, identitas material tidak jelas.

\section{Saran}

Saran yang penulis berikan dalam penelitian ini khususnya untuk PT. XYZ antara lain: Perusahaan dapat menerapkan quality tools seperti Fault Tree Analysis dan Failure Mode And Effect Analysis dalam upaya pengendalian kualitas produk kecap untuk mengendalikan kegagalan pada produk, memberikan traning dan SOP yang jelas dan mudah dipahami oleh semua orang diruang lingkup PT. XYZ dan memberikan pemahaman yang sepaham antara setiap operator dan berbagai departemen sehingga tidak adanya gap atau perbedaan pendapat antara operator, upaya perbaikan tools oleh perusahaan pada proses produksi, maintenance mesin rutin dan terjadwal, serta melakukan meeting secara berkala dengan karyawan untuk mempermudah manajemen menyampaikan perbaikan perbaikan yang perlu dilakukan oleh karyawan.

\section{DAFTAR PUSTAKA}

Ansori, N., \& Mustajib, M.I. (2013). Sistem Perawatan Terpadu (IMS). Yogyakarta : Graha Ilmu.

Bayu, Asep Nama Rukmana, Iyan Bachtiar (2017). Perbaikan Kualitas Produk Tepung Kaolin Dengan Metode Fault Tree Analysis (FTA) Dan Failure Mode And Effect Analysis (FMEA). (Di Pt. Industrial Mineral Indonesai Provinsi Bangka Belitung). Prodi Teknik Industri. Universitas Islam Bandung. Jl. Tamansari No.1 Bandung 40116.

Gasperz, V. (2012). Manajemen Toolbook. Bogor : Tri-Al-Bros Publising.

Heizer \& Render. (2014). Manajemen Operasi. Jakarta : Graha Ilmu.

Hendy Tannady. (2015). Pengendalian Kualitas. Jakarta : Universitas Bunda Mulia Lodan.

Irja Zein (2015). Penentuan Penyebab Kecacatan Produk Sabun Dengan Metode Fault Tree Analysis (FTA) Dan Failure Mode And Effect Analysis (FMEA). (Di Pt. Oleochem dan Soap Industry Medan). Jurusan Teknik Industri. Sekolah Tinggi Harapan Medan.

Irnanda Pratiwi, Hermanto MZ, Faizah Suryan (2018). Analisis Penyebab Kecacatan Produk Roti Pia Dengan Menggunakan Metode Fault Tree Analysis (FTA) Dan Failure Mode And Effect Analysis (FMEA). (Studi Kasus di Home Industry Sahabat Cake). Fakultas Teknik. Universitas Tridinanti Palembang.

Ninda Restu Anugrah, Lisye Fitria, Arie Desrianty (2015). Usulan Perbaikan Kualitas Produk Menggunakan Metode Fault Tree Analysis (FTA) Dan Failure Mode And Effect Analysis (FMEA). 
Jurusan Teknik Industri. Institut Teknologi Nasional (Itnes) Bandung.

Poppy Febriyana. Dewi Shofi Mulyati. Iyan Bachtiar. (2016). Usulan Perbaikan Kualitas Produk Kaos Kaki Dengan Metode Fault Tree Analysis (FTA) dan Failure Mode And Effect Analysis (FMEA). (Studi Kasus : Home Industry Citra Iqra Pratama). Program Studi Teknik. Universitas Islam Bandung. Jl. Tamansari No.1 Bandung. 217.

Richma Yulinda Hanif. Afif. (2015). Perbaikan Kualitas Produk Keraton Luxury di PT. X Dengan Menggunakan Metode Fault Tree Analyisis (FTA) Dan Metode Failure Mode Effect Analyisis (FMEA). Program Studi Teknik Industri Fakultas Sains dan Teknologi. Uniersitas Al Azhar Indonesia. Komplek Masjid Agung Al Azhar, Jl Sisingamangraja, Kebayoran Baru, Jakarta Selatan 12110.

Sony Mubaro, Muhammad Iqbal (2018). Analisa Kecacatan Pada Produksi Sepatu Nike G40 Dengan Metode Failure Mode And Effect Analysis (FMEA) Dan Merancang Perawatan Mesin PU (Polyurethane) Sol Sepatu Di Pt. XYZ. Program Studi Teknik Industri Fakultas Sains dan Teknologi. Uniersitas Al Azhar Indonesia. Komplek Masjid Agung Al Azhar, Jl Sisingamangraja, Kebayoran Baru, Jakarta Selatan 12110.

Sony Mubarog. Faisal. (2017). Analisa Kecacatan Pada Produksi Sepatu NIKE G40 Dengan Metode Fault Tree Analyisis (FTA) Dan Metode Failure Mode Effect Analyisis (FMEA). Home Industry Citra Iqra Pratama). Program Studi Teknik. Universitas Islam Bandung. $\mathrm{Jl}$. Tamansari No.1 Bandung. 217.
Yadi Ahmad Fauzi, Hilmi Aulawi (2016). Analisis Pengendalian Kualitas Produk Peci Jenis Overset Yang Cacat Di Pd. Panduan Ilahi Dengan Menggunakan Metode Fault Tree Analysis (FTA) Dan Failure Mode And Effect Analysis (FMEA). (Jurnal Kalibrasi). Sekolah Tinggi Teknologi Garut. Jl. Mayor Syamsu No. 1 Jayaraga Garut 44151 Indonesia.

Yadi Ahmad Fauzi. Hilmi Aulawi. (2016). Analisis Pengendalian Kualitas Produk Peci Jenis Overset Yang Cacat Di PD. Panduan Ilahi Menggunakan Metode Fault Tree Analyisis (FTA) Dan Metode Failure Mode Effect Analyisis (FMEA). Sekolah Tinggi Teknologi Garut. Jl. Mayor Samsu No.1 Jayaraga Garut. 30 - 33 . 
Akbar Supriadi, Daonil, Iskandar Zulkarnaen

Submitted: 12/03/2020; Revised: 01/04/2020; Accepted: 21/04/2020; Published: 29/06/2020 